\title{
AVALIAÇÃO “PORÇÃO NOROESTE” EM RELAÇÃO A OCUPAÇÃO DOS ESPAÇOS URBANOS NO MUNICÍPIO DE SENADOR CANEDO EM GOIÁS: ESTUDO DE CASO
}

\author{
Evaluation "northwest portion" in relation to the occupation of urban spaces in the municipality of \\ Senador Canedo in Goiás: case study
}

\author{
Antônio Henrique Capuzzo Martins * \\ Beatriz Ribeiro Soares ** \\ João Dib Filho ***
}

\begin{abstract}
*Docente do Instituto Federal de Goiás - capuzzoifg@gmail.com. ** Docente da Universidade Federal de Uberlândia - brsoares@ufu.br.

*** Docente do Instituto Federal de Goiás - joao.dib.f@gmail.com.
\end{abstract}

\author{
Recebido em 06/05/2018. Aceito para publicação em 25/06/2018. \\ Versão online publicada em 10/08/2018 (http://seer.ufrgs.br/paraonde)
}

\begin{abstract}
Resumo: 0 texto relata um estudo de caso em relação aos "vazios urbanos" identificados dentro de uma porção, área delimitada, no município de Senador Canedo, sendo observado no espaço de tempo de 10 anos de transformação do município. Salienta-se, ainda, uma verdade da necessidade de alerta sobre a implantação de loteamentos urbanos, sem considerar a real necessidade e diretrizes reais de ordenamento urbano, a fim de disciplinar tal crescimento.
\end{abstract}

Palavras-chave: Vazios Urbanos; Expansão Urbana.

\begin{abstract}
The paper reports a study case in regarding the "urban voids" identified within a portion, enclosed area, in the municipality of Senador Canedo, being observed in the gap of 10 years of municipal transformation. It's also emphasized a real need of warning about the implantation of urban settlements without considering the actual necessity, and without regarding the actual guidelines of urban planning, in order to dicipline such growth.
\end{abstract}

Key-words: Urban Voids; Urban Sprawl.

\section{Introdução}

O crescimento da cidade de Goiânia há muito ultrapassou os limites municipais, compondo uma mancha urbana que inclui várias cidades, fazendo com que, hoje, nela se inclua o segundo maior município do Estado de Goiás, o município de Aparecida de Goiânia. No todo, Goiânia e seu entorno concentram uma população urbana.

Essa expansão urbana fez com que antigos distritos se tornassem municípios autônomos, ou bairros e municípios autônomos se tornassem cidades dormitórios ou, ainda, literalmente, bairros, configurando um processo parecido com aquele observado pelo arquiteto Flávio Vilaça na cidade de São Paulo, de que ela é devoradora de cidades e uma produtora de bairros (VERGARA; ACCORSI, 1999).

Ao final do século, Goiânia e seu entorno concentram uma população de, aproximadamente, 1,5 milhão de habitantes e o que se afigurava como um aglomerado urbano, toma, agora, a forma conurbada, eliminando-se os vazios urbanos. 0 que não significa o fim da expansão da periferia, mas a sua redefinição dada pelo surgimento dos enclaves. Provocando o seu deslocamento além dos núcleos urbanos conurbados ou a sua recriação nas fímbrias da cidade-metrópole, como se verifica na região sul de Goiânia, onde se desenvolveram vários bairros sob a influência do processo de ocupação acelerada da capital e completamente inseridos na sua dinâmica. 
O crescimento demográfico - decorrente da migração de pessoas de outras Regiões brasileiras -, a fragmentação sócio espacial e a necessidade da reforma urbana - como pré-requisito para democratização da cidade -, fazem da região metropolitana de Goiânia um rico objeto de pesquisa.

Este crescimento transforma as cidades, em potencial, em grandes objetos de riqueza das incorporadoras / imobiliárias onde, através de influências políticas, acabam se favorecendo das leis aprovadas, inclusas nos planos diretores, principalmente no quesito limite de expansão urbana.

A origem de Senador Canedo está relacionada à Goiânia, com a estrada de ferro da Rede Ferroviária Federal. 0 crescimento da cidade ocorreu na trilha aberta na construção da ferrovia, e as primeiras famílias trabalhadoras eram oriundas do estado de Minas Gerais e Bahia.

O nome da cidade é uma homenagem ao senador Antônio Amaro da Silva Canedo, primeiro representante do estado de Goiás em cenário nacional. Em 1953, o povoado foi elevado à condição de distrito de Goiânia e em 1988, a Assembleia Legislativa de Goiás aprovou a emancipação do município. Foi sancionada como Lei 10.435 de 09 de janeiro de 1988 pelo então governador Henrique Santillo.

Destaca-se também, atualmente, o polo petroquímico, com diversas empresas do setor situadas na proximidade da cidade, entre outras está a Petrobrás.

\section{Especulação Imobiliária}

A especulação imobiliária, portanto, caracteriza-se pela distribuição coletiva dos custos de melhoria das localizações, ao mesmo tempo em que há uma apropriação privada dos lucros provenientes dessas melhorias. Essas melhorias que acabam valorizando os terrenos podem dar-se de muitas formas; as mais comuns referem-se à provisão de infraestrutura (água, esgoto, energia), serviços urbanos (creches, escolas, grandes equipamentos urbanos) e às melhorias realizadas nas condições de acessibilidade (abertura de vias, pavimentação, sistema de transporte, etc.).

Tais melhorias, quando realizadas no entorno de um terreno, acabam agregando-lhe maior valor. Terrenos com boa infraestrutura são mais caros que terrenos sem nenhuma infraestrutura. 0 mesmo vale para a pavimentação das vias. Outro caso relativamente comum é o de terrenos que não são muito bem localizados, até que uma nova avenida ou rua importante é aberta, melhorando suas condições de acessibilidade. Seu preço, por consequência, aumenta quase que instantaneamente.

Outra forma de melhoria da localização acontece pelo simples acréscimo de novas edificações no seu entorno, o que por si só torna sua acessibilidade melhor em relação ao conjunto da cidade. Em outras palavras, a ocupação por atividades (residenciais, comerciais, etc.) ao redor de um terreno torna-o mais próximo - e portanto com maior acessibilidade - a uma nova gama de possibilidades de interação com o resto da cidade. Essa possibilidade de interação, por sua vez, é um aspecto valorizado pelas pessoas no momento de escolher um determinado local e, por isso, acaba também contribuindo para o aumento do preço do solo.

Observa-se que "melhoria" de uma localização é o processo através do qual a qualidade da localização de um terreno em relação à disponibilidade de infraestrutura e a outros terrenos (e, portanto a outras atividades e centros de interesse) é aumentada. Dessa forma, os terrenos chamados "de engorda" ficam vazios, à espera que o desenvolvimento da cidade se encarregue de valorizá-los, sem que nenhum investimento tenha sido feito pelo proprietário (a não ser, é claro, o IPTU, que, no entanto é irrisório comparado à valorização da terra). Todo o investimento foi feito pelo Poder Público, principalmente no caso das infraestruturas, e por outros proprietários privados.

Para entender esse ponto de vista, é interessante fazer uma comparação: imagine um empreendedor qualquer, que queira ter lucro através da realização de uma determinada atividade. Para conseguir isso, ele tem que investir uma certa quantia de capital e correr um risco, proporcional à probabilidade de o negócio dar certo ou não. Os ganhos, por sua vez, também serão proporcionais ao risco corrido. Ele presta um serviço que, de uma maneira ou de outra, é útil à coletividade e, em 
troca desse serviço prestado, recebe sua compensação financeira. Nesse processo, ele gera empregos e movimenta a economia.

Por outro lado, o especulador imobiliário que investir a mesma quantia de capital em um terreno ocioso não está contribuindo em nada para a sociedade. Não gera empregos, não presta nenhum tipo de serviço, e pior: ainda traz inúmeros prejuízos para a coletividade, conforme será visto mais adiante. Ainda assim, por causa da valorização imobiliária conseguida através de investimentos feitos por outros setores da sociedade, alcança lucros muitas vezes bastante grandes.

Outra maneira de "melhorar" a localização de uma área é melhorar a qualidade dessa localização em relação ao resto das áreas disponíveis no mercado, através do acréscimo de novas áreas que sejam piores que elas. Assim, às vezes o preço de um determinado terreno sobe sem que haja nenhuma modificação no seu entorno. Isso acontece porque loteamentos são criados nas piores localizações, normalmente na periferia, isolados do tecido urbano e em condições precárias de infraestrutura. Entretanto, mesmo esses loteamentos têm que, no mínimo, cobrir seus gastos de produção e conferir algum lucro ao empreendedor, definindo, portanto, os menores preços do mercado de terras.

Com isso, o "ranking" de localizações é rearranjado, pela introdução, na sua base, de uma nova "pior" localização. As outras localizações, por consequência, passam a ser mais valorizadas, por estarem agora mais "distantes" da pior localização e mais próximas das áreas mais interessantes da cidade, ao menos em comparação com essas novas áreas que agora passaram a fazer parte do tecido urbano. Quando um terreno deixa de ser uma das piores localizações, pela adição de novas piores localizações, seu preço sobe automaticamente.

Na maioria das vezes, esse mecanismo está associado também à forma mais básica da especulação imobiliária, uma vez que deve ser feita provisão de infraestrutura para atender a essas piores localizações, e que essa infraestrutura acaba passando pelos terrenos mais bem localizados, valorizando-os ainda mais.

As dificuldades de deslocamento da população de mais baixa renda, especialmente nas grandes cidades, também é, em grande parte, decorrente dessa lógica especulativa, que aumenta as distâncias entre habitação e empregos. A urbanização de "piores" localizações empurra a ocupação para lugares cada vez mais distantes, e com isso as distâncias que os novos moradores têm que percorrer acaba aumentando.

Diante da constatação desses problemas advindos da especulação imobiliária, alguns instrumentos urbanísticos vêm sendo utilizados para tentar coibi-la, com destaque especial para aqueles regulamentados pelo Estatuto da Cidade.

O IPTU progressivo no tempo, por exemplo, permite ao poder público sobretaxar aqueles imóveis que não estiverem cumprindo sua função social, isto é, que estiverem sendo subaproveitados em áreas que possuam infraestrutura.

A outorga onerosa do direito de construir busca recuperar parte dos investimentos do poder público em infraestrutura decorrentes do aumento de densidade acarretado por aquelas edificações cuja área ultrapasse a área do terreno (coeficiente 1).

A contribuição de melhoria permite que o poder público cobre dos proprietários beneficiados por obras de melhoria urbana o valor do investimento.

Entretanto, a aplicação de tais instrumentos nem sempre são implementadas, mesmo com a nova leva de planos diretores participativos, principalmente por causa de hábitos e crenças há muito tempo arraigados na cultura do brasileiro. Como explicar a alguém que sempre viu seus pais e avós segurando a venda de terras para esperar os melhores preços que agora ele não poderá mais fazer isso, sob pena de pagar mais impostos? Tarefa difícil, mas que deve ser levada a cabo paulatina e constantemente, para que seja possível modificar essa mentalidade e criar cidades mais justas para todos. 


\section{O olhar das oportunidades de especulação o município de Senador Canedo - Go}

O surgimento do Estatuto das Cidades, que delineava diretrizes para elaboração de Plano Diretores, tendo como conceito sendo um instrumento básico de um processo de planejamento municipal para a implantação da política de desenvolvimento urbano, norteando a ação dos agentes públicos e privados (ABNT, 1991).

Seria um plano que, a partir de um diagnóstico científico da realidade física, social, econômica, política e administrativa da cidade, do município e de sua região, apresentaria um conjunto de propostas para o futuro desenvolvimento socioeconômico e futura organização espacial dos usos do solo urbano, das redes de infraestrutura e de elementos fundamentais da estrutura urbana, para a cidade e para o município, propostas estas definidas para curto, médio e longo prazos, e aprovadas por lei municipal. (VILLAÇA, 1999, p. 238).

Para grande maioria dos municípios do país, tinha como grande objetivo também a questão social, que é colocar em condições, famílias de classe baixa, de adquirir seu terreno e por consequência construir sua habitação. Zonas de interesses sociais foram criadas em planos diretores, onde são empregados em novos loteamentos terrenos com áreas entre 200 e $250 \mathrm{~m}^{2}$, que teoricamente teriam valores mais acessíveis. Com implantação do Programa Minha Casa Minha Vida (PMCMV), partir de março 2008, houve um verdadeiro estouro no mercado imobiliário e por consequência no ramo da construção civil. As facilidades que o programa, veio que inflacionar o mercado imobiliário, tornando um efeito cascata em valorização. Assim surgiram várias oportunidades de novos loteamentos, principalmente em regiões metropolitanas.

No caso de Senador Canedo houve oportunidades novas de implantação de loteamentos, partir da dos novos marcos de expansão urbana, implantados no Plano Diretor do município, através da lei municipal no 1317 de 28 de dezembro de 2007 (Figura 1). Estes novos limites permitiram que novos loteamentos pudessem serem aprovados, sem que tivessem o cuidado de observar a real necessidade de implantação em determinadas regiões do município e também sem que houvesse uma leitura de não se criar novos vazios urbanos.
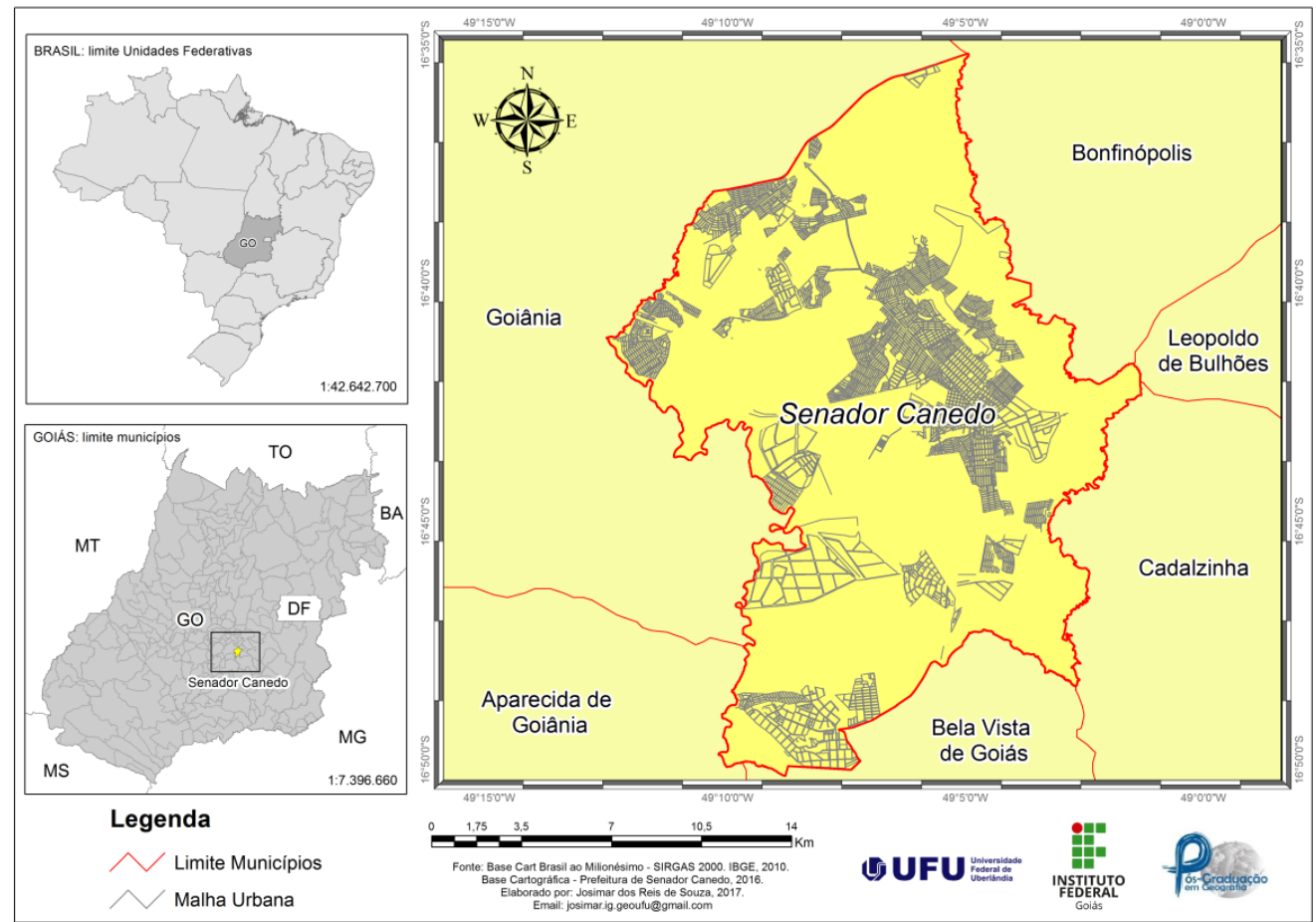

Figura 1 - Localização do Município de Senador Canedo - GO

Fonte: Prefeitura Municipal de Senador Canedo - GO, 2016. 
A supervalorização do preço da terra, tendo em vista processos especulativos, em decorrência do superaquecimento da demanda é a questão mais preocupante: o aporte de subsídios federais para a construção de 1 milhão de casas (PAC 1) e mais 2 milhões de casas (PAC 2) pela iniciativa privada provocou uma verdadeira corrida a terrenos, o que fez sumir os espaços ainda vazios para construção e o preço do metro quadrado disparar, principalmente nas periferias dos grandes centros (FÓRUM NACIONAL DE SECRETÁRIOS DE HABITAÇÃO E DESENVOLVIMENTO URBANO - FNSHDU, 2010).

Segundo alguns autores, "Vazios urbanos constituem-se normalmente de espaços não construídos e não qualificados como áreas livres no interior do perímetro urbano de uma cidade. A definição, no entanto, varia entre diferentes autores: espaços como parques podem eventualmente ser considerados "vazios urbanos" em algumas definições e noutras não, visto que constituem-se de espaços urbanos com função social. Da mesma forma, também podem ser considerados "vazios urbanos" grandes vazios demográficos em áreas urbanas densamente construídas - o que rompe que a ideia de que "vazio urbano" seja um espaço sem construção alguma. Processos como os de gentrificação, degradação e abandono do Estado de algumas regiões urbanas levam à sua desocupação parcial ou total, ou à substituição do perfil populacional, reduzindo as densidades locais. Desta forma, áreas que antes eram densamente ocupadas podem vir a se transformar em vazios populacionais no interior das cidades. Grandes espaços efetivamente vazios também podem ser resultado da transformação de usos urbanos, como os de antigas áreas ferroviárias, portuárias e fabris. Em cidades que passaram por alteração do perfil econômico nas últimas décadas do século XX (especialmente naquelas de perfil industrial que passaram a apresentar caráter predominantemente terciário), notam-se normalmente grandes espaços abandonados e estruturas construídas vazias, como galpões, pátios de manobra e logística, docas, entre outros, que agora não mais possuem função e encontram-se ociosos."

Tentando fazer parte de grupos de autores, em definir vazios urbanos, sem nenhuma pretensão de provocar uma discussão maior, tenho como conceito a intepretação de que qualquer lote que em determinado tempo, desde o surgimento do loteamento no qual ele foi empregado, considero como vazio urbano, pelo fato de que área de regiões metropolitanas estão cada vez mais valorizadas, e observando que no período de 2008 até recentemente, houvesse um super aquecimento de valores, em função do cenário político-econômico no qual empregado.

Em 2002 o município de Senador Canedo começou um processo de transformação, tendo novos olhares principalmente das grandes imobiliárias/incorporadoras, buscando novos negócios neste município, iniciando assim a partir daí um processo de ocupação maior. Assim, principalmente em determinada região do município, onde podemos nomear de porção Noroeste do município houvesse um processo de ocupação da mesma principalmente a partir de 2005, em crescente maior a partir de 2009 e demonstrado em 2014.

Nesta avaliação podem ser observados um processo crescente de surgimento de "novos vazios urbanos", que em determinado processo de avaliação de quantificação desde então, podem-se ser determinado em termos percentuais, em relação a cada área delimitada (conforme Figura 2 e Tabela 1).

Identificamos dentro da área delimitada em linha amarela na figura 6, cinco áreas que forma enumeradas de I a V, onde foram interpretados em percentual a quantidade de lotes vagos, considerados dentro de um conceito, como vazio urbano. 

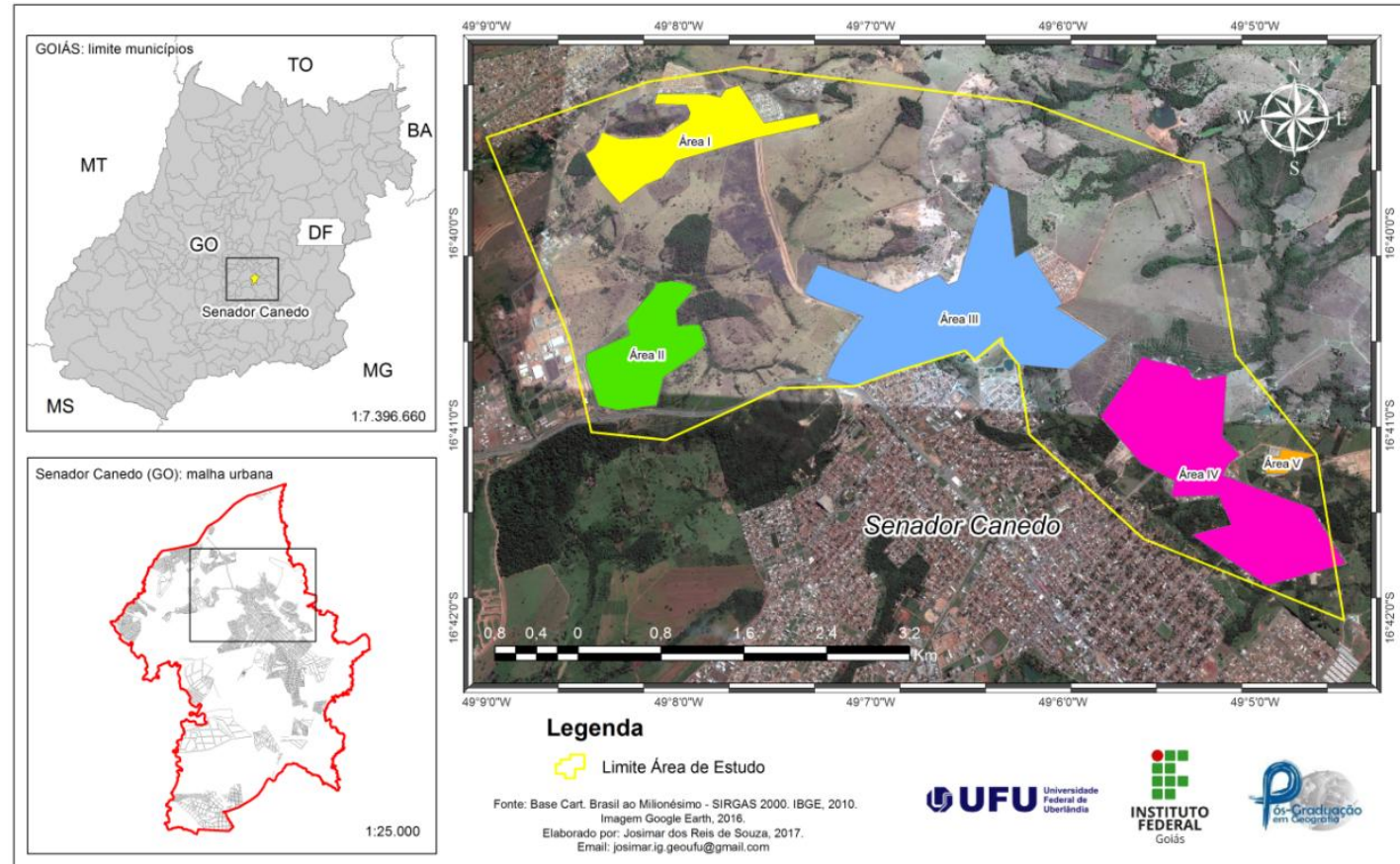

Figura 2 - Imagem de 2014 de Senador Canedo - GO

Fonte: GOOGLE EARTH, 2015.

Tabela 1 - Quantificação de "Vazios Urbanos"

\begin{tabular}{|c|c|c|c|c|}
\hline ÁREA & $\begin{array}{l}\text { TOTAL DA } \\
\text { ÁREA }\left(\mathrm{Km}^{2}\right)\end{array}$ & $\begin{array}{c}\text { TOTAL ÁREA } \\
\text { URBANIZÁVEL (No } \\
\text { LOTES DE } 250 \mathrm{~m}^{2} \text { ) }\end{array}$ & \% ANALISADO EM VAZIOS & $\begin{array}{l}\text { QUANTIDADE DE LOTES NÃO } \\
\text { OCUPADOS (LOTES DE } 250 \mathrm{~m}^{2} \text { ) }\end{array}$ \\
\hline ÁREA I & 1,19 & 2.285 & 40,00 & 914 \\
\hline ÁREA II & 0,65 & 1.248 & 97,00 & 1.211 \\
\hline ÁREA III & 2,68 & 5.146 & 25,00 & 1.286 \\
\hline ÁREA IV & 1,68 & 3.226 & 15,00 & 484 \\
\hline ÁREA V & 0,14 & 269 & 100,00 & 269 \\
\hline $\begin{array}{l}\text { Total / } \\
\text { MÉDIA }\end{array}$ & 6,34 & 12.173 & - & 4.164 \\
\hline
\end{tabular}

Fonte: Martins, 2015.

Analisando os resultados apresentados na Tabela 1, ressalta-se que cada área observada, corresponde mais de um loteamento. Todas áreas foram medidas em escala, utilizando software apropriado, e quantificados em áreas urbanizável, considerando um índice de aproveitamento de $48 \%$ em relação a área total e transformado em número de lotes, com área de $250 \mathrm{~m}^{2}$ cada. A partir daí é realizado uma análise em cima da imagem de satélite, quantificando os vazios em relação a cada área, e também transformado em número de lotes não ocupados(vazios). Observando os resultados, vale ressaltar que de um total de 12.173 de possíveis lotes serem criados no total das áreas de I a V, foi encontrado 4.164 lotes não ocupados ("vazios urbanos"), que representa $34,20 \%$ em relação ao total.

Vale ressaltar que dentro desta análise, pelo menos 1 em cada 3 lotes lançados torna-se em um lote não ocupado (vazio urbano), tendo um peso de qualquer forma, na otimização operacional por parte do município. 


\section{Considerações Finais}

Vale compreender que embora pareça ideal ter espaço de sobra quando tantas cidades enfrentam o "inchaço" urbano, os lotes vazios gerados pela especulação imobiliária e lançamentos desnecessários custam caro para a população. Nós temos muito mais infraestrutura do que seria necessário e isso torna os serviços de energia, água, asfalto, coleta de lixo e transporte coletivo muito mais caros. É como uma família que tivesse que arcar com despesas de uma área de $250 \mathrm{~m} 2$, mesmo que utilizasse apenas 30\% dela. Devemos ainda considerar que o município de Senador de Canedo, tem ainda um peso maior na observação de custos operacionais, pois o mesmo é responsável pelo sistema de tratamento de água e esgoto (SANESC), sendo dentro da região metropolitana o único que não pertence a empresa de responsabilidade do estado, que é SANEAGO. Para o município em análise, vale ressaltar que ter responsabilidade em administrar sistema de tratamento de água e esgoto, torna-se um peso maior para o mesmo, simplesmente pela falta de investimentos ao longo do mesmo período em análise, e que poderiam ter pelo menos igualar em condições de obter tal expansão. Isso é mesurado, principalmente em época de seca, notícias de falta de água em parte considerável do município, em especial na mesma "porção noroeste" do município, ou ao mesmo tempo retirando água de alguns loteamentos, com sistema independente, como é o caso dos Residenciais Paraíso e Paraíso II, que em determinada época através caminhões pipa, fornecem água pra outros bairros que estão em falta.

Ainda no campo de infraestrutura o município de certa forma organizou-se, de forma planejada, para investir no sistema de tratamento de esgoto, já que o mesmo possui ainda $0 \%$ de tratamento de esgoto. Ao longo do mesmo tempo em análise, foram realizados projetos, identificado áreas para implantação das ETE'S, delineado diretrizes para aprovação de projetos de loteamentos, com exigências de redes de esgotos, mesmo que "seca", pois não possuem condições de serem ligadas, mesmo assim, foram insuficientes para tal demanda de aprovação realizada e implantada. Tal ritmo de aprovação tornou-se um problema analisado pelo próprio Ministério Público do estado, determinado junto a prefeitura que a mesma interrompesse durante 2 anos, aprovação de novos loteamentos, que foi dentro do período em análise.

Seria Lemos insiste ainda interessante que houvesse a importância de impedir a expansão do perímetro urbano nos próximos dez anos, mas vale lembrar que são necessários mecanismos que forcem o uso dos lotes ociosos.

A expansão desenfreada, tendo como propósito ao atendimento do interesse do capital e também do grande empreendedor, obriga o ente público a estender suas infraestruturas, tipo agua, luz, esgoto, coleta de lixo, segurança pública, postos de saúde, creches e escolas, transporte público nas quais o dono do capital investido nestes loteamentos praticamente se isentam de responsabilidades e até mesmo dos custos na implantação destes, e em alguns empreendimentos atuais, os mesmos doam pequenas áreas para algumas execuções de postos, que ainda sim, repetindo, não são de responsabilidades destes. Mas a implementação destes serviços e postos de atendimento, valorizam ainda mais o empreendimento dos incorporadores e até mesmo os lotes e ou áreas adquiridas pelos especuladores. Tem-se ainda o interesse e a necessidade de empresas privadas de investirem para atenderem estes empreendimentos, como por exemplo as empresas de telefonia e bancos.

Surge ainda, as quentões ligadas ao transporte, seja ele público ou por meios próprios, como os realizados por motos e carros, onde desencadeiam variáveis que impactam os indicadores de acidentes, volume de trafego que desembocam nas vias principais de acesso, seja rumo aos centros comerciais de Senador Canedo, seja os de Goiânia.

Nisto tudo, percebe-se de forma direta que os custos de toda esta engrenagem do capital, impactará num sobrepreço dos impostos IPTU IPVA Taxas de agua, esgoto iluminação, contas de telefonia, dentre outros, e estas práticas de estado e do capital de repassarem os custos e aumentarem os lucros, sobre cairá na sociedade, seja ela a de consumo seja ela a sociedade comum. 
Assim, distanciara ainda mais o cidadão necessitado e trabalhador, da aquisição e da manutenção de um lote, seja ele para um possível investimento seja ele para um futuro recente empreendimento imobiliário, e por consequência, a efetiva e tão sonhada casa própria.

\section{Referências}

AMPOS FILHO, Candido Malta. Cidades brasileiras: seu controle ou o caos. 4 ed. São Paulo: Studio Nobel, 2001. 143 p.

ASSOCIAÇÃO BRASILEIRA DE NORMAS TÉCNICAS. NB 1350 - Normas para elaboração de plano diretor. Rio de Janeiro: ABNT, 1991.

BRASIL. Estatuto da Cidade: guia para implementação pelos municípios e cidadãos. 2 ed. Brasília: Câmara dos Deputados, Coordenação de Publicações, 2002.

MOYSÉS, Aristides; BORGES, Elceni. A retomada dos financiamentos públicos imobiliários e a produção para os setores populares: impactos na reconfiguração espacial da RM de Goiânia. Rio de Janeiro: ANAPUR, 2011. p. 1-23.

SABOYA, Renato. Concepção de um sistema de suporte à elaboração de planos diretores participativos. 2007. 232 f. Tese (Doutorado em Engenharia Civil) - Universidade Federal de Santa Catarina, Florianópolis, 2007.

O que é especulação imobiliária?. In: Urbanidades, Urbanismo, Planejamento Urbano e Planos Diretores, 2008. Disponível em: http://urbanidades.arq.br/2008/09/o-que-e-especulacaoimobiliaria. Acessado em: maio de 2017.

SILVA, José Afonso. Direito urbanístico brasileiro. São Paulo: Malheiros, 1995. 476 p.

VILLAÇA, Flávio. Dilemas do Plano Diretor. In: CEPAM. O município no século XXI: cenários e perspectivas. São Paulo: Fundação Prefeito Faria Lima - CEPAM, 1999. p. 237-247. 